\title{
Image Analysis of Periapical Radiograph for Bone Mineral Density Prediction
}

\author{
Rini Widyaningrum ${ }^{1}$, Sri Lestari ${ }^{2}$, Ferry $\mathrm{Jie}^{3}$ \\ ${ }^{1}$ Department of Dentomaxillofacial Radiology, Faculty of Dentistry, Universitas Gadjah Mada, Yogyakarta, Indonesia \\ ${ }^{2}$ Electrical Engineering, Faculty of Science and Technology, University of Respati Yogyakarta, Indonesia \\ ${ }^{3}$ Edith Cowan University, Western Australia, Australia
}

\begin{tabular}{l} 
Article Info \\
\hline Article history: \\
Received Jan 19, 2018 \\
Revised May 21, 2016 \\
Accepted May 28, 2018 \\
\hline
\end{tabular}

Keyword:

Area parameter

Integrated density

Osteoporosis

Periapical

Radiograph

Trabecular bone

\begin{abstract}
Osteoporosis is a systemic skeletal disease. Parameter from any bone site in the body has possibility to be developed as a predictor of osteoporosis. The alteration in the mandible trabecular bone is visible in periapical radiographs. The aim of this study was to correlate the area parameter and the integrated density of periapical radiograph with bone mineral density. Image analysis of periapical radiograph i.e. measurement of area parameter and integrated density was done on Region of Interest (ROI) by using canny edge detection method. Result of this study showed that the area parameter has asignificant $(\alpha<0.05)$ negative correlation with the bone mass density (BMD) of the lumbar spine $(r=-0.371)$ and $\mathrm{T}$-score of the lumbar spine $(\mathrm{r}=-0.383)$. The linear regression test showed that the area parameter only can be used to predict $\mathrm{T}$-score of the lumbar spine $(\mathrm{F}=5.822, \alpha<0.05)$. The integrated density showed a significant $(\alpha<0.05)$ negative correlation with T-score of hip $(r=-0.332)$ and T-score of lumbar spine $(r=-0.377)$. It can be concluded that the area parameter can be used as one of input parameters for computeraided system of osteoporosis early detection by using periapical radiograph.
\end{abstract}

Copyright $@ 2018$ Institute of Advanced Engineering and Science. All rights reserved.

\section{Corresponding Author:}

Rini Widyaningrum,

Department of Dentomaxillofacial Radiology,

Faculty of Dentistry,

Universitas Gadjah Mada,

Jl. Denta, Sekip Utara, Yogyakarta, Indonesia.

Email : rinihapsara@ugm.ac.id

\section{INTRODUCTION}

Osteoporosis is one of systemic skeletal disease. Low bone mineral density and alteration of bone architecture become the indicators for osteoporosis. The effect of this condition is the higher fragility of the bone, so that the risk for bone fracture increased[1]. The trabecular bone is a type of skeletal tissue that has a spongy appearance [2]. The trabecular bone connectivity is one of the manifestation of bone quality beside the geometrical of bone, microarchitecture of bone, and cortical thickness. The condition of trabecular bone of the normal and osteoporotic bone is shown in Figure 1 [3]. Some studies in dentistry also proved that osteoporosis in the hip and lumbar spine would also manifest as osteoporosis in the jaw bone, especially in the lower jaw bone (the mandible) [4]. A control program especially for early detection of osteoporosis conducted by The Ministry of Health of Republic Indonesia as 2 of 5 Indonesian people have a risk of osteoporosis [5].

The radiography, is an integral procedure on dental examinations to produce a radiographic image. This technique applies X-rays as sources for imaging objects. The radiograph shows the different level of radiopacity influenced by difference attenuation coefficient $(\mu)$ of the object as expressed by Beer-Lambert law in Equation (1) [7]. 
$\ln \frac{I}{I_{0}}=-\mu x$
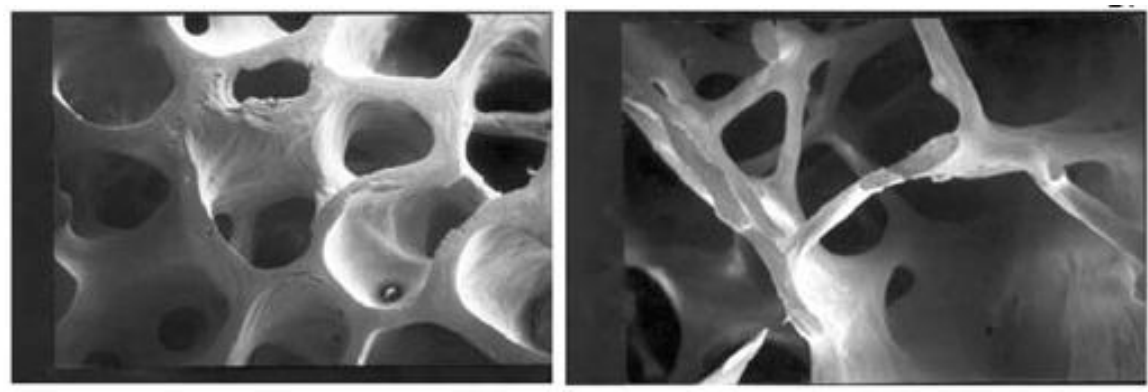

Figure 1. The trabecular bone of normal bone (left) and the osteoporotic bone (right) [6]

With I is X-rays intensity passing through a certain material (object), I0 is the initial intensity of $\mathrm{X}$-rays before passing object, $\mu$ is the linear attenuation coefficient, and $\mathrm{x}$ is the thickness of the material. As attenuation coefficient is a function of X-ray energy and the thickness of the object, the interation between $\mathrm{X}$-ray with parts of the object will result in a difference image radio-opacity [8]. A high density object will be visualized totally radiopaque. While a less dense object will be visualized as a totally radiolucent. The differences of attenuation coeeficient will be visualized as gray level [9].

Not only the quality of x-ray beam, but also the bone mineral density become an important thing for detecting osteoporosis using radiograph. As the density and the atomic number of the mineral, combined with the thickness of the penetrated bone determine the absorption of X-ray by the tissue. As the BMD decreased, the bone structure will be changes, so that the absorption of $\mathrm{x}$-ray beam decreased. It can be observed by a radiograph [10].

Dual X-ray absorptiometry (DEXA) is the gold standard of bone mineral density examination approved by WHO [11]. Because of the relatively high cost and limited availability of DEXA equipment, it is worth looking for alternative diagnostic techniques for bone mineral density examination [12]. In the other hand, several X-ray imaging equipment for biomedical examination is more available in hospitals and health centers than DEXA, including dental X-ray imaging equipment for oral and maxillofacial radiography.

The postmenopausal woman has a high risk of osteoporosis due to the decreased of estrogen after they experience menopause. Those who have alterations on the jaw bone (mandible and maxilla) has a possibility of having a risk for low bone density or even suffering from osteoporosis [13]. The possibility of a postmenopausal woman to visit the dentist to get dental treatment is higher than their possibility to go to the hospital to get osteoporosis examination. Dental radiography is a common examination used by the dentist to determine the diagnosis and treatment planning [14], [15]. Therefore the dental radiograph is highly potential to be developed as an instrument for osteoporosis detection.

Osteoporosis manifestation on the mandible (lower jaw) and the maxilla (upper jaw) which visible on the dental radiograph is becoming such interesting studies in the last 2 decades. Some previous studies show that osteoporosis screening can be done by trained dentists by using panoramic radiograph [4]. Osteoporotic bone alteration on the mandibular cortical bone is visible on panoramic radiograph and can be easily seen by a dentist. Whereas the mandible trabecular bone alterations related with osteoporosis also visible on periapical radiographs as well as panoramic radiographs [12], [16], [17]. The periapical radiography is a low-cost examination. X-ray equipment for this radiography technique is being mostly available in dental clinics and hospitals.

Meanwhile, the prognosis of osteoporosis treatment will be better when it is detected earlier [15]. For that reason, studies to develop early detection of osteoporosis is becoming challenging. And also, if the symptoms of osteoporosis were able to be detected earlier, hopefully the patient would get proper medication to prevent to osteoporotic fracture. A computer-aided diagnosis (CAD) system was developed in previous study [17] using the parameter of mandibular cortical bone erotion on the panoramic radiograph. However, the result of the system may be influenced by observers' diagnostic performance [17]. Some previous studies showed that image analysis also can be applied in periapical radiograph to predict the osteoporosis condition [16]-[20]. The combination of BMD and texture parameter values reported to provide a better assessment of the fracture risk than that obtainable by BMD measurement only [21]. There were many 
previous study about osteoporosis detection using periapical radiograph, but there were few references in the subject of Indonesian post-menopausal women.

The area parameter and the integrated density are measurement parameters that can be used in image analysis. Those parameters were applied to periapical radiographs in this study to predict the bone mineral density. The aim of this study was to correlate the area parameter and the integrated density of periapical radiograph with the bone mineral density of the hip and lumbar spine. The area parameter and the integrated density of periapical radiograph were expected to become the indicator of the trabecular pattern alteration on the mandible, which potential to be developed as osteoporosis predictor. A method developed by using periapical radiograph in this study may be used as osteoporosis screening instrument or computeraided system for the dentist. Furthermore, we hope that the result of this study can contribute to provide a literature, especially in the study of osteoporosis detection using periapical radiograph for Indonesian women.

\section{RESEARCH METHOD}

Samples of this study were bone mineral density data and periapical radiographs from 37 postmenopausal woman. To obtain the bone mineral density data, every subject on this study was scanned by using DEXA on their hip and lumbar spine. The DEXA examination to measure the bone mineral density of the hip and lumbar spine was done in The Dr. Sardjito General Hospital, Yogyakarta, Indonesia, by using Lunar Prodigy Primo DEXA densitometer (GE Lunar Corporation, Madison, WI, USA) with exposure of $42 \mu \mathrm{Gy}$ in 1.27 minutes. The bone mineral density expressed in bone mass density (BMD) and T-score. Those result of DEXA scan were interpreted by the radiologist refers to the World Health Organization classification for diagnosis of osteoporosis based on T-score (Table 1) [11]. The periapical radiograph used in this study have passed the quality assessment by the dentist. High quality and correctly positioned periapical radiographs were included into the study. This study obtained the ethical approval No. 00681/KKEP/FKGUGM/EC/2016 from the ethics and advocacy unit, faculty of dentistry, Universitas Gadjah Mada, Yogyakarta, Indonesia.

Table 1. WHO Classification for Diagnosis of Osteoporosis based on T-Score [11]

\begin{tabular}{ll}
\hline \multicolumn{1}{c}{ Diagnosis } & \multicolumn{1}{c}{ T-score } \\
\hline Normal & $>-1,0$ \\
Osteopenia & $<-1,0$ or $>-2,5$ \\
Osteoporosis & $<-2,5$ \\
Severe Osteoporosis & $<-2,5$ with the presence of one or more fragility fracture \\
\hline
\end{tabular}

The independent variable of this study were the area parameter and integrated density from the periapical radiograph. While the dependent variable were the bone mineral density from DEXA scan, like in the previous study [22]. The periapical radiography was done in The Prof Soedomo Dental Hospital, Faculty of Dentistry, Universitas Gadjah Mada, Yogyakarta, Indonesia. This examination was done by using Villa Sistemi Medicali Endos ACP CEI dental X-ray (Bologna, Italy) and a photostimulable phosphor plate (PSP) image receptor. Periapical radiography exposure was using $70 \mathrm{kVp}, 8 \mathrm{~mA}$, and the exposure time was $3.2 \mathrm{~s}$.

Image processing was done by using canny edge detection method in ImageJ $1.50 \mathrm{i}$ software, a version of Wayne Rasband, National Institutes of Health, USA (http://imagej.nih.gov/ij). ImageJ is in the public domain (https://imagej.nih.gov/ij/download.html) (Accessed on 14 April 2016, Java 1.6.0_20) to measure the area parameter and the integrated density of the region of interest (ROI) of periapical radiograph as seen in Figure 2.

The ROI was taken from the trabecular bone at the anterior region of the mandible in periapical radiographs. The ROI selection has been done by dentist supervision. Measurement of area parameter and integrated density was done after the dentist approved the ROI selection. Images of the ROI were not in the same size for each radiograph, depend on each condition of the mandible. That was the reason why the ROI must be approved by the dentist. Canny edge detection was applied to the ROI image from all periapical radiographs. This edge detection method allows us to get the best result represent the real edge of the object captured in the radiograph. The result of canny edge detection showed the edge pattern similar to the skeletonized image, and become input data for measurement process to obtain the area parameter and the image density.

The area parameter was obtained by measuring the fraction area divided by the total area of the ROI. Whereas the integrated density calculates and displays two values (the product of Area and Mean Gray

Image Analysis of Periapical Radiograph for Bone Mineral Density Prediction (Rini Widyaningrum) 
Value). For the uncalibrated image, the integrated density can be defined as the sum of the values of the pixels in the image or selection. Either area parameter or integrated density was obtained by measuring the ROI using ImageJ $1.50 \mathrm{i}$ software. While the plugin for canny edge detector is available on http://imagej.net/plugins/canny/index.html.

The Spearman's correlation test was done for both area parameter and integrated density of periapical radiograph with the bone mineral density (BMD and T-score). Then the linear regression test was done to determine whether the area parameter or integrated density of periapical radiograph can be used as a predictor for the bone mineral density of the hip and lumbar spine.
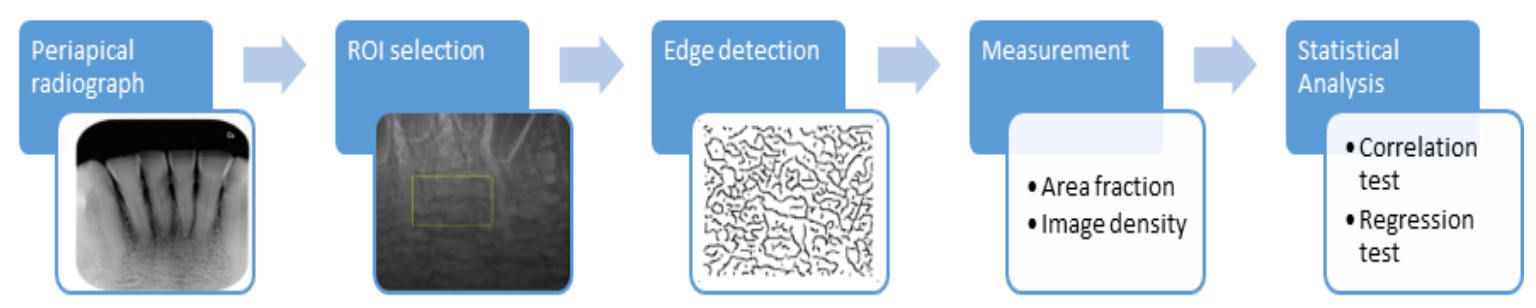

Figure 2. Flowchart of the study

\section{RESULTS AND DISCUSSION}

\subsection{Result}

Image processing was done to extract the information in periapical radiographs of the mandible to get the predictor parameter for bone mineral density of the hip and lumbar spine. The Canny edge detection applied to each ROI, then the area parameter and the integrated density were measured. As there were 37 radiographs and DEXA scanning, the result of measurement also 37 data. All radiographs passed the quality assurance, so there were no data has to be excluded in this study.

The statistical analysis applied the Spearman's correlation test and the linear regression test. The result of Spearman's correlation test between the area parameter and the integrated density of periapical radiograph with the bone mineral density is shown in Table 2. The bone mineral density involves BMD of hip, T-Score of hip, BMD of the lumbar spine, and T-Score of the lumbar spine.

Table 2. The result of Spearman's Correlation test between the area Parameter and the Integrated Density with the Bone Mineral Density

\begin{tabular}{lcccc}
\hline \multicolumn{1}{c}{$\begin{array}{c}\text { Correlation } \\
(\mathrm{r}, \alpha)\end{array}$} & $\begin{array}{c}\text { BMD } \\
\text { hip }\end{array}$ & T-Score hip & $\begin{array}{c}\text { BMD } \\
\text { lumbar spine }\end{array}$ & $\begin{array}{c}\text { T-Score lumbar } \\
\text { spine }\end{array}$ \\
\hline r of the area parameter & -0.210 & -0.236 & $-0.371^{*}$ & $-0.383^{*}$ \\
$\alpha$ of the area parameter & 0.219 & 0.166 & 0.026 & 0.021 \\
r of the integrated density & -0.193 & $-0.332^{*}$ & -0.311 & $-0.377^{*}$ \\
$\alpha$ of the integrated density & 0.260 & 0.048 & 0.065 & 0.023 \\
\hline
\end{tabular}

The linear regression test has been done to determine whether the area parameter can be used as a predictor for the bone mineral density. Table 3 shows the result of linear regression test between the area parameter with the bone mineral density.

Table 3. The result of Linear Regression Test between the area Parameter with the Bone Mineral Density

\begin{tabular}{|c|c|c|c|c|}
\hline Value & $\begin{array}{l}\text { BMD } \\
\text { Hip }\end{array}$ & $\begin{array}{l}\text { T-Score } \\
\text { hip }\end{array}$ & $\begin{array}{l}\text { BMD } \\
\text { lumbar spine }\end{array}$ & $\begin{array}{l}\text { T-Score lumbar } \\
\text { spine }\end{array}$ \\
\hline $\mathrm{r}$ & 0.160 & 0.290 & 0.302 & 0.382 \\
\hline $\mathrm{R}^{2}$ & 0.025 & 0.084 & 0.091 & 0.146 \\
\hline $\mathrm{F}$ & 0.888 & 3.122 & 3.423 & $5.822 *$ \\
\hline Sig & 0.353 & 0.086 & 0.073 & 0.021 \\
\hline $\mathrm{T}$ & -0.943 & -1.767 & -1.85 & $-2.413 *$ \\
\hline Sig & 0.353 & 0.086 & 0.073 & 0.021 \\
\hline $\mathrm{A}$ & 0.906 & 0.545 & 1.212 & 1.46 \\
\hline $\mathrm{B}$ & -0.013 & -0.189 & -0.026 & -0.265 \\
\hline
\end{tabular}


The result of the linear regression test of the integrated density with the bone mineral density can be seen in Table 4.

Table 4. The result of Linear Regression Test between the Integrated Densities with the Bone Mineral

\begin{tabular}{|c|c|c|c|c|}
\hline \multicolumn{5}{|c|}{ Density } \\
\hline Value & $\begin{array}{l}\text { BMD } \\
\text { Hip }\end{array}$ & $\begin{array}{l}\text { T-Score } \\
\text { hip }\end{array}$ & $\begin{array}{l}\text { BMD } \\
\text { lumbar spine }\end{array}$ & $\begin{array}{l}\text { T-Score lumbar } \\
\text { spine }\end{array}$ \\
\hline $\mathrm{r}$ & 0.117 & 0.207 & 0.294 & 0.322 \\
\hline$r^{2}$ & 0.014 & 0.043 & 0.087 & 0.104 \\
\hline $\mathrm{F}$ & 0.474 & 1.515 & 3.221 & 3.938 \\
\hline Sig & 0.496 & 0.227 & 0.082 & 0.055 \\
\hline $\mathrm{t}$ & -0.689 & -1.231 & -1.795 & -1.984 \\
\hline Sig & 0.496 & 0.227 & 0.082 & 0.055 \\
\hline $\mathrm{A}$ & 0.809 & -0.928 & 1.041 & -0.582 \\
\hline B & $-4.57 \mathrm{E}-08$ & $-6.67 E-07$ & $-1.26 \mathrm{E}-07$ & $-1.19 \mathrm{E}-06$ \\
\hline
\end{tabular}

\subsection{Discussion}

Digital image processing techniques has been applied in previous studies to improve the image quality [23] as well as to assist the identification of pathological condition by using radiograph [16] and other imaging modality [7]. The image processing in this study employed edge detection method to measure the area parameter and the integrated density parameter. This method also used in the previous study to get uterus shape by using the ultrasonography image [23]. The Canny edge detection was developed based on three criteria that make it be an optimal edge detector. These three criteria were a low error rate, well localized of edge point pixel, and only one response to a single edge [24].

Statistical analysis has been applied to determine the correlation between both of area parameter and integrated density of periapical radiographs with bone mineral density data. The Spearman's correlation test (Table 1) showed that there were a weak significant negative correlation between the area parameter with BMD of lumbar spine $(\alpha<0.05 ; r=-0.371)$ and T-score of lumbar spine $(\alpha<0.05 ; r=-0.383)$ respectively. On the other hand, the correlation between the area parameter with the BMD and T-Score of hip did not statistically significant. These results may be correlated with the differences in the percentage of trabecular bone on each site (lumbar spine and hip). Trabecular bone in lumbar spine has a higher percentage $(66 \%)$ than those in the hip (25\%) [25].

The negative correlation between the area parameter with BMD and T-score of the lumbar spine as shown in Table 2, osteoporotic condition on spine indicated by the higher value of area parameter in the periapical radiograph. The condition of low bone mineral density may induce perforation on the trabecular bone of mandible that can be characterized by the increase of small areas in the radiograph. The result of this study agrees with previous studies [16], [17]. Bone perforation can be indicated by the decrease of connectivity in trabecular bone. The connectivity of trabecular bone will decrease as the perforation increase.

Based on the linear regression test of area parameter in this study as shown in Table 3, significant $\mathrm{F}$ value $(\alpha<0.05)$ only for the $T$ score of the lumbar spine $(F=5.822)$. Furthermore, the linear regression test shows that the area parameter only potential to predict $\mathrm{T}$-score of the lumbar spine. The negative sign of the slope (A) indicates that the T-score of lumbar spine will decrease along with the increase of the area parameter. While there were no other significant $\mathrm{F}$ and $\mathrm{t}$, means that the area parameter is not suitable to predict the BMD of hip, T-score of hip, and the BMD of the lumbar spine. This can be explained that the trabecular bone of lumbar spine has a high percentage that is $66 \%$.

The determination coefficient (R-square) of area parameter with T-score of the lumbar spine (Table 3) was 0.146 . It means that the influence of area parameter to T-score of the lumbar spine was $14.6 \%$ while the rest $(85.4 \%)$ are determined by another parameter. The correlation strength for area parameter with T-score of the lumbar spine was only in weak level $(\mathrm{r}=0,382)$. The result of this study also suitable with previous studies, which showed that the parameter of the periapical radiograph also has a weak correlation strength with bone mineral density [17], [26]. Those parameters were texture [17] and maximum value [26] of the periapical radiograph. So that those parameters cannot be determined as a predictor for the bone mineral density in lumbar spine as well as hip. This condition may be influenced by the fact that the bone mineral density examination and both of the area parameter and the integrated density measurement were done in different sites. The DEXA examination was applied for bone mineral density measurement in the hip and lumbar spine while periapical radiographs were used to obtain the area parameter and the integrated density of the anterior region of mandible [17], [19].

The Spearman's correlation test as shown in Table 1 for the integrated density parameter showed an intermediate and significant $(\alpha<0.05)$ negative correlation with T-score of hip $(r=-0.332)$ and T-score of 
lumbar spine $(r=-0.377)$. But it has a weak correlation and did not show significant correlation with the BMD of hip and BMD of the lumbar spine. In the other hand, the linear regression test as shown in Table 4 between the integrated density parameter with the bone mineral density of the hip and lumbar spine have no significant $\mathrm{F}$ and $\mathrm{t}(\alpha>0.05)$. It means that the integrated density is not suitable to predict the bone mineral density, neither BMD nor the T-score of hip and lumbar spine.

The area parameter and integrated density characterized the trabecular bone connectivity which determines the quality of bone. Bone quality is a manifestation of bone architecture (bone geometry, microarchitecture, cortical thickness, and trabecular connectivity), bone matrices, and bone mineralization. Bone mineral density has a high correlation with the risk of bone fracture, and it can be used by the physician to determine the needs of pharmacological intervention for the patient [3].

Bone density of a particular region becomes the main predictor of fracture risk for its specific region. Patients with osteoporosis on their spine are not certainly having osteoporosis on their hip or mandible. But physician and dentist must be considered that osteoporosis is a systemic skeletal disease so that studies to obtain the predictor for osteoporosis using radiograph on another site besides hip and lumbar spine have a probability to be developed. This probability is valuable in fact that DEXA equipment needs high cost and its availability is being limited in particular public health services, especially in Indonesia. For that reason, a computer-aided system will be necessary to overcome the DEXA limitation. The area parameter can be used as a predictor or input parameter for the computer aided system of osteoporosis early detection.

Based on previous study [22], there are four steps to build the computer aided system of osteoporosis early detection, i.e. to identify the risk of osteoporosis by using dental radiograph, to make the application software for early detection of osteoporosis, to train the software for the introduction for the normal bone, and to apply the design of osteoporosis early detection software for the dentist. Previous study has applied it in digital image processing of radiograph for identification of lung cancer [22]. This study is the first step of four complete steps to build the computer aided system of osteoporosis early detection.

\section{CONCLUSION}

The area parameter of periapical radiograph has a significant negative correlation with the BMD of lumbar spine and T-score of the lumbar spine. The linear regression test showed that the area parameter can be used to predict T-score of the lumbar spine. The parameter of integrated density showed a significant negative correlation with T-score of hip and T-score of the lumbar spine, but result of the linier regression test showed that the integrated density cannot be used as a predictor of BMD or T-score, neither for hip nor lumbar spine. The integrated density may be potential to be a predictor of bone mass density by using the different image processing method before the parameter measurement. The Canny edge detection method and the area parameter in this study can be developed to build a computer-aided system for osteoporosis screening by using periapical radiograph. While the parameter of integrated density may be suitable to be combined with the other image processing method beside canny edge detection method.

\section{ACKNOWLEDGEMENTS}

The authors gratefully acknowledge the support by the Badan Penerbit dan Publikasi Universitas Gadjah Mada, Yogyakarta, Indonesia.

\section{REFERENCES}

[1] J. E. Adams, "Dual-energy X-ray absorptiometry," Med. Radiol. Diagnostic imaging Radiat. Oncol., vol, 2, pp. 105-124, 2008.

[2] K. J. Jepsen, "Systems Analysis of Bone," Wiley Interdiscip Rev Syst Biol Med, vol. 1, no. 1, pp. 73-88, 2010.

[3] W. T. Ayoub, "Osteoporosis: Clinical Guidance for Prevention, Diagnosis, and Management," in Diagnostic Test and Interpretation, D. R. Gueldner, S.H., Grabo, T.N., Newman, E.D., and Cooper, Ed. New York: Spinger Publishing Company, 2008, pp. 33-40.

[4] A. Taguchi et al., "Risk of vertebral osteoporosis in post-menopausal women with alterations of the mandible," Dentomaxillofac Radiol, vol. 36, pp. 143-148, 2008.

[5] Ministry of Health of Republic Indonesia, "Guidelines for Osteoporosis Control," Minist. Heal. Decree No.1142/MENKES/SK/XII/2008, 2008.

[6] National Osteoporosis Foundation, Clinician's Guide and Treatment. Washington DC: BoneSource, 2008.

[7] S. Sushma and S. Prasanna Kumar, "Advancement in Research Techniques on Medical Imaging Processing for Breast Cancer Detection,” Int. J. Electr. Comput. Eng., vol. 6, no. 2, p. 717, 2016.

[8] K. S. Krane, Modern Physics, 3rd ed. USA: John Wiley \& Sons, Inc, 2012. 
[9] S. Lestari, W. Nugroho, and G. B. Suparta, "Metode ekstraksi informasi fisis multi-citra radiografi digital," J. Fis. Indones., vol. 13, pp. 48-56, 2009.

[10] M. Jergas, "Radiology of Osteoporosis," in Medical Radiology Diagnostic Imaging and Radiation Oncology, 2nd ed., A. L. Baert, L. W. Brady, H. P. Heilmann, M. Knauth, M. Molls, C. Nieder, and K. Sartor, Eds. Verlag Berlin Heidelberg: Spinger, 2008, pp. 77-104.

[11] G. M. Blake and I. Fogelman, "The role of DXA bone density scans in the diagnosis and treatment of osteoporosis," Postgr. Med J, vol. 83, pp. 509-517, 2007.

[12] R. Licks, V. Licks, F. Ourique, H. R. Bittencourt, and V. Fontanella, "Development of a prediction tool for low bone mass based on clinical data and periapical radiography," Dentomaxillofacial Radiol., vol. 39, pp. 224-230, 2010.

[13] A. Taguchi et al., "Observer performance in diagnosing osteoporosis by dental panoramic radiographs: Results from the osteoporosis screening project in dentistry (OSPD)," Bone, vol. 43, no. 1, pp. 209-213, 2008.

[14] K. Ishii et al., "Diagnostic efficacy of alveolar bone loss of the mandible for identifying postmenopausal women with femoral osteoporosis," Dentomaxillofac Radiol, vol. 36, pp. 28-33, 2007.

[15] P. C. A. Watanabe et al., "Morphodigital study of the mandibular trabecular bone in panoramic radiograph," Int.J.Morphol, vol. 25, no. 4, pp. 875-880, 2007.

[16] E. I. Sela, S. Hartati, A. Harjoko, R. Wardoyo, and M. Mudjosemedi, "Feature Selection of the Combination of Porous Trabecular with Anthropometric Features for Osteoporosis Screening,” Int. J. Electr. Comput. Eng., vol. 5, no. 1, pp. 78-83, 2015.

[17] S. Lestari, G. B. Suparta, and N. Kertia, "The Correlation between Texture Parameter of Mandible Trabecullar Bone with The Bone Mass Density Value Frame of Theory," in The 7th ICBEMA BME-Days 2012, November 9th-10th, 2012, vol. 7, pp. 107-110.

[18] W. G. M. Geraets, J. G. C. Verheij, P. F. Van Der Stelt, K. Horner, and C. Lindh, "Selecting regions of interest on intraoral radiographs for the prediction of bone mineral density," Dentomaxillofac. Radiol., vol. 37, pp. 375-379, 2008.

[19] R. Widyaningrum and S. Lestari, "The Correlation between Mandible Trabecular Texture Parameter on Panoramic Radiograph with Bone Mass Density,” Proc Int. Symp. oral Dent. Sci., pp. 206-214, 2013.

[20] E. I. Sela, S. Hartati, A. Harjoko, R. Wardoyo, and S. M. M, "Segmentation on Dental Periapical X-Ray Images for Osteoporosis Screening," Int. J. Adv. Comput. Sci. Appl., vol. 4, no. 7, pp. 147-151, 2013.

[21] E. Lespessailles et al., "Clinical interest of bone texture analysis in osteoporosis: A case control multicenter study," Osteoporos. Int., vol. 19, no. 7, pp. 1019-1028, 2008.

[22] B. G. Irianto, M. R. Mak, and D. Titisari, "Identification of Lung Cancer Using a Back Propagation Neural Network," TELKOMNIKA (Telecommunication Computing, Electrics and Control), vol. 16, no. 1, pp. 91-97, 2015.

[23] R. Supriyanti, Y. Ramadhani, H. B. Widodo, and T. I. Rosanti, "Brightness and Contrast Modification in Ultrasonography Images Using Edge Detection Results," TELKOMNIKA (Telecommunication Computing, Electrics and Control), vol. 14, no. 3, pp. 1090--098, 2016.

[24] R. Maini and H. Aggarwal, "Study and Comparison of Various Image Edge Detection Techniques," Int. J. Image Process., vol. 3, no. 1, pp. 1-12, 2009.

[25] S. L. Bonnick, Bone Densitometry in Clinical Practice, Application and Interpretation, 3rd ed. New York: Humana Press, 2010.

[26] S. Lestari, M. Diqi, and R. Widyaningrum, "Measurement Of Maximum Value Of Dental Radiograph To Predict The Bone Mineral Density," in International Conference on Electrical Engineering, Computer Science and Informatics (EECSI), 2017 4th, 2017, pp. 156-159.

\section{BIOGRAPHIES OF AUTHORS}

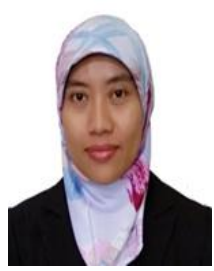

Rini Widyaningrum is a dentist and also a lecturer in Faculty of Dentistry, Universitas Gadjah Mada. Her field of study is Dentomaxillofacial Radiology. She has graduated as a dentist from Faculty of Dentistry, Universitas Gadjah Mada, Yogyakarta, Indonesia. She continued her study in Biomedical Engineering program in Graduate School, Universitas Gadjah Mada. Her thesis was The Relationship between Bone Mass Density and Radiomorphometry Index on Menopausal Women from Javanesse Ethnic in Indonesia. Currently, Rini is studying as a doctoral student in Faculty of Dentistry, Universitas Gadjah Mada. Her research interest are oral and maxillofacial radiology, radiographic image enhancement, digital image processing of dental radiograph, and photoacoustic imaging.

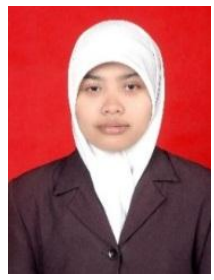

Sri Lestari received the Bachelor degree in Physics Department, Faculty of Mathematics and Science, Gadjah Mada University, Yogyakarta, Indonesia. From her bachelor degree, she focused on the radiography image processing. Her thesis was radiographic image processing for early detection of osteoporosis using periapical radiograph in Biomedical Engineering, Biotechnology, Universitas Gadjah Mada in 2012. Currently, Lestari is a lecturer in Faculty of Science and Technology, Universitas Respati Yogyakarta. Lestari's current research is in biomedical engineering especially in electromedical engineering. She has authored 12 research publication including 4 international proceeding and 1 international journal since 2009 to 2017. 
Ferry Jie has graduated his doctorate study from The University of Sydney in 2008. His PhD thesis is Supply Chain Analysis in the Australian Beef Industry. Currently Dr Jie is an Associate Professor at School of Business and Law, Edith Cowan University. Previously, he was a Senior Lecturer and taking a program coordinator role in Logistics and Supply Chain Management (LSCM) at RMIT University. He was managing and coordinating the undergraduate program in LSCM at RMIT from 2015 to 2016. Dr Jie has maintained a high quality of research throughout his academic career including international scholarly leadership in the areas of supply chain management and logistics, including being invited to be keynote speaker and to give public lectures at symposiums and international conferences in Indonesia, Malaysia, Vietnam, China and Australia. From 2011 to 2016, Dr Jie has published 17 refereed journal articles (including 6 (six) articles in A Ranked Journal - ABDC Journal Lists) and 15 refereed conference papers. Furthermore, Dr Jie has received research grants/awards to the amount of $\$ 204,604.07$ between 2010 and 2016. Dr Jie has professional and community engagement activities to contribute significantly to improve the university's reputation through contribution to the wider community. 